\title{
Determinants of Community Involvement: A Review of Literature and New Hypotheses
}

\author{
Salisu Aliyu Abubakar ${ }^{1, *}$, and Bahtiar Mohamad ${ }^{1}$ \\ ${ }^{1}$ School of Multimedia Technology and Communication, 06010 UUM Sintok, Kedah, Malaysia
}

\begin{abstract}
This article provides an understanding of what community relations is all about. From the numerous literatures consulted, it observe that relationship between companies, and their various host communities was characterized by conflict destruction and misunderstanding but sometimes positives. Against this background, a new framework on community involvement was proposed as a response to the failing attempts by several recommendations and model on how to improve community relations. Furthermore, this paper's attempt to unravel what need to be done in creating and enabling environment that will bring about peace, understanding and patronage. This article argues that, community involvement enhances effective participation of host community. However, based on the proposed model, the determinants of community involvement are: trust, control mutuality, commitment and satisfaction. This linkage of determinants to community involvement could only be relevant if the company agreed to work together, based on what this paper hypothesised in line with the assumption of social exchange theory.
\end{abstract}

\section{Introduction}

A community relation is an organizational strategic function of reaching out to various stakeholders, especially host communities with a view to fostering understanding [1]. Similarly, a community relation is a technique of monitoring the concern of host communities, and to building rapport to earn long-term support of community members. It is an organizational internal mechanism which reduces risks that might confront companies [2]. The variety of risk includes: host community's activism, boycott of company's product and even negative media coverage.

Companies utilize community relations strategy to promote mutual benefit with their stakeholders, especially their host communities. Globally, companies employed various programmes in order to improve their relationship with host community to improve understanding and support [3]. Managing relationship that can benefit both company and the host community is the ground for contemporary community relations.

Several decades, company community relationship has been characterized as unfriendly and hostile, but sometimes positive [4]. In recent times, the violent conduct of host communities' towards business firms, especially multi-national company is alarming,

*Corresponding author: mbahtiar@uum.edu.my 
and the restiveness is prevailing [5], leading to several incidences of killings, kidnapping, boycott and vandalize of properties, and sometimes lead to temporal or permanent shutdown of a business site. However, this predicament has now compelled companies to be decisive in looking down an avenue to patch up their dispute with their respective host communities. Therefore, in order to address these negative and harmful effects causes to the environment and the inhabitants; companies ought to engage in developmental community activities, empower the inhabitant and address the imbalance in terms of resource allocation and utilization [6] by involving host community in the decision making and other activities. Genuine involvement with the community and transparency has been described as a panacea to improving community relations, but that could only be achieved through the help of relationship determinants: trust, control mutuality, commitment and satisfaction respectively.

Therefore, this paper intends to review literature and develop new hypotheses on the determinants of Community Involvement.

\section{Review of Literature}

A community relation is a multi-dimensional field, which various scholars viewed differently. For instance, it is aims at ensuring that stakeholders, particularly host community need to be integrated into developmental activities that will improve their lives, with the view to earn patronage [1]. The focus on this definition is on company's interest, because by doing well you will get better.

Furthermore, community relations aimed at resolving dispute or rancour that is capable of threatening harmonious coexistence between companies and their various stakeholders. For instance, the environmental effect caused by company's activities, is the basis of several conflicts between companies and host communities. Therefore, the best and suitable way to address it is through dialogue and appropriate consultation. Based on the above listed definitions of community relations, it is observed that three characteristics of community relations have been highlighted below thus:

Involvement: To achieve an enduring community relation, companies should have supposed to carry local community along in developmental programmes. Involving community through a developmental initiative comes in a different form such as educational support, youth empowerment, social welfare and even providing aid to the needy societies, and more importantly these new ways of involvement are blended in company's core area of proficiency for business strategy and marketing [7]. Lack of involving community members is largely the major causes of misunderstanding and rancour between companies and community.

Communication as a basis for dialogue: Communication serves as fundamental means of creating and enabling environment for understanding between company and host community. Communication is a veritable tool for resolving conflict and proper solution through consolation. Communication management entails effective supervision of free flow of information and organizational external relations, which consist of public issues and engagement with social groups, the media and other related agencies [8]. An effective two ways flow of communication gives room to monitor any change or variation in community attitude or anticipation, so as quickly take the necessary measures which could result to commitment and satisfaction between company and community.

Based on the identified characterization of community relations, this paper adopted community involvement as the most effective instrument of building harmonious coexistence between companies and their host communities. However, community involvement could only sustain only if it is built based on trust, control mutuality, commitment and satisfaction respectively [9]. 


\section{Research Frameworks and Hypotheses Development}

In line with the objective of this paper that is to review literature and develop new hypotheses on the determinants of Community Involvement. Conceptual model is designed to further signify the causative relationship within the various constructs, and other factors influence community involvement. Figure 1 indicates the key constructs.

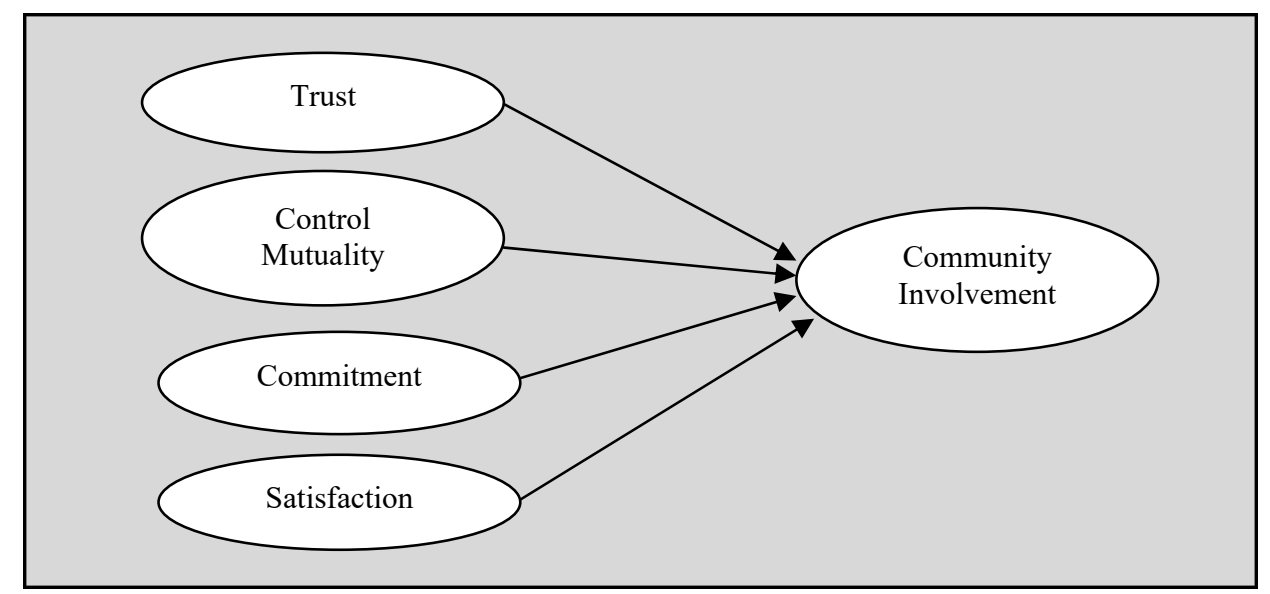

Fig. 1. The proposed model of the antecedents' Community Involvement

The antecedents of community involvement and relationship determinants are trust, commitment, satisfaction, and control mutuality.

\subsection{The Relationship between Trust and Community Involvement}

According to [10], trust is defined as one party's level of assurance in readiness to be submissive to transact with the other party. Trust, however, can bring about tranquillity with one another and strengthen the relationship between two or more individuals in relationship or between organization and community. Similarly, trust is a significant component which aids organisations or companies in actualizing their goals and aspiration, because is a cordial linkage that bond organizational system. In support of above assertion, [11] affirm that, trust depicts to extend of reliance and determination upon one party's readiness in fulfilling its commitment toward another.

Although these variable's trust and community involvement are different concepts, but they have a significant linked, because the degree to which local communities are involved in company in community development activity heavily relied on the understanding and relationship that have been built between them. In reality, [12], asserted that, in-depth consultation by the company to its various key stakeholders, especially local community base on clear and openness throughout the implementation activity are vital ingredients of a 
genuine community development. This according to [13] could only be attained if host community are deeply involved and inform about a certain key decision by either the company, organisation, or even government authority in taken decision that directly affects the community.

Previous researchers have identified trust as a veritable instrument for determining a relationship between companies and their various stakeholders, particularly host communities, but [14] found out in their study that, trust is not a determinant in an online business purchase relationship, but rather people heavily rely on interactivity.

There is no empirical confirmation so far in relationship between trust and company community involvement, moreover to support the position that there exists a link several studies attested to that [15]. Considering the above discussion, it is pertinent to propose that:

Proposition 1: The level of trust between a company and host community will positively affect involvement of community.

\subsection{The Relationship between Control Mutuality and Community involvement}

There exist a relationship between control mutuality and community involvement. Even though the two concepts are different, but they shared a link. Control mutuality according to [16] is the degree in which parties consent on who has the authority to influence the other party. While, it is a new adopted business imitative by the companies in engaging their local host community by giving them, a sense of belonging and seeks a competitive advantage. Corporate community involvement entails how companies engaged stakeholders in the deliberations and executions of various developmental programmes that are targeted at achieving effective community relations and development.

The aim of every business is to make significant profit and compete favourably among the competitors; therefore, this could not be achieved without effective community relations, in other words, the business would not prosper in tense environment, so a key to effective community relations is through involving the local populace, so that they could have a sense of belonging. There exist a link between control mutuality and community involvement is in the area of meeting stakeholder's expectation, especially host community. Every company that deliberately overlooks community expectation by refuse to involve them in the company's community developmental programmes or other related activities that concern them, then the company will have itself to blame. Taking into cognizance the above discussion so far, it therefore, propose that:

Proposition 2: There is a significant impact of control mutuality of a company with host community involvement.

\subsection{The Relationship between Commitment and Community involvement}

Commitment was defined as a degree to which relationship is sustained, even to the extent of compromising some immediate needs to secure long-term interest [17]. Commitment has also been defined as the extent to which each party's readiness and believe that the relationship is worth been sustained and promote to next level. Many scholars asserted that commitment signifies how partners look at target a successful and persistent relationship [18]. It is important to note that, the current debate among researchers on business and society, emphasize that, organization and companies competing in the market circles should strive to demonstrate their ethical commitment by providing their audience with satisfying information concerning product content and social services. 
It is interesting to note that, many US giant companies and other reputable firms around the world are shifting their focus by devoting substantial time and resources towards community involvement initiative, which comprises of capacity development and skill acquisition, corporate support and other developmental project because gradually companies have realised that, for them to be faithfully accepted as neighbor of choice and have their license to operate, they must exhibit uttermost commitment by involving host community in their developmental activities [19].

Although scholars shared different views on how company's commitment shaped their relationship with host community. According to [20], companies lack of internal coordination in their developmental projects are the reasons behind failures of several community relations programmes, because it has been shown that in spite, the huge amount budgeted for community developmental programmes by multinationals companies, some host communities are not convinced with the level of company's commitment because they have not been involved throughout the process and execution. A study by [21] further re affirmed this position that huge investment alone without compliment it with internal commitment will not bring the desired result.

Commitment towards community developmental projects measured company's readiness in providing essential services in improving the general wellbeing of society and benefit company's business competitive advantage [22]. This form of initiative helps in fostering mutual trust and understanding, and subsequently brings an economic advantage to the company. Considering the above discussion, it is therefore proposed that:

Proposition 3: The level of a Company's commitment will positively influence host community involvement.

\subsection{The Relationship between Satisfaction and Community involvement}

Satisfaction is described as the degree to which both parties have the impression that the relationship is favourable to them because of real expectation of the outcome characterized satisfaction as enjoyable attainment [23]. Literature reveals that, significant number of researches conducted on satisfaction viewed it as either on product or service evaluation derived from. However, this study intended to identify the satisfaction as an evaluation of relationship outcome between company and host community.

A number of researches have established the relationship between satisfaction and community involvement. This is evidently clear on how people evaluate community satisfaction with an outcome of various levels of involvement within the community setting [24]. Thus, network structure within the community determines their satisfaction. The community with solid and formidable structure of involvement and networking are susceptible in bringing a diverse group of settlers such as investors together and reach an accepted goal.

Even though satisfaction has been described as the fulfilment derived from the service been rendered or delighted with the situation but in some cases brand reputation or organizational reputation plays a significant role in relationship building rather than the actual satisfaction from the service been rendered. However, [25], have contrary findings. Their study reveals that satisfaction is not a key a factor of shaping relationship. Considering on the above discussion; therefore, this study proposed that:

Proposition 4: There is a significant impact of host community's satisfaction and the level of community involvement. 


\section{Conclusions}

Based on the above analysis, the proposed model explains how community involvement companies can provide companies with various benefits that can transform into quality and beneficial relationship, between companies and host communities. Another valuable expected contribution to be derive from this paper, is that, companies wish to embark on community relations activities to improve their harmonious coexistence with host communities, will find this article relevant. Furthermore, this article will be useful to managers and practitioners in suggesting to their respective companies as well as all their representatives as to what project is suitable and desirous of the host communities.

This paper deliberated on the research framework as well as the hypothesis development. The framework is designed as a mechanism to develop a causal effect of relationship between determinants and community involvement in the relations between company and host community. Furthermore, highlighted are the antecedents of community involvement, which are: Trust, satisfaction, commitment and control mutuality respectively. The paper ends with showing link between various construct and hypotheses as proposed accordingly. Based on this, we proposed this model.

\section{References}

1. B. W. Altman, Business and Society Review, 102(1), 43-51. (1999)

2. K. Rehbein, \& D. A. Schuler, Business \& Society, 54(6), 794-821. (2015)

3. C. Sengupta, International Education and Research Journal, 2(6).11-12 (2016)

4. A, Hassan, \& R. Kouhy, R. International Journal of Energy Sector Management, 9(2), 204-226. (2015)

5. F. E. Nlerum, \& M. D. Epepe, Open Access Library Journal, 2(12) 1-7. (2015)

6. C. P. Lin, Y. H. Tsai, S. W. Joe, C. K. Chiu, Journal of business ethics, 105(1), 83-93. (2012)

7. D. Hess, N. Rogovsky, T. W. Dunfee, California Management Review, 44(2), 110125. (2002)

8. S. A. Waddock, \& M. E. Boyle, California Management Review, 37(4), 125-140. (1995)

9. J. E. Grunig, \& L. A. Grunig, A Report for the Department of Energy Office of Science. Department of Communication. University of Maryland. (2001)

10. Y. H. Huang, Y. H. Journal of public relations research, 13(1), 61-90. (2001)

11. A. Sharma, \& R. Kiran, African Journal of Basic \& Applied Sciences, 4(3), 95-105. (2012)

12. S. Du, \& E T. Vieira Jr, Journal of Business Ethics, 110(4), 413-427. (2012)

13. A. M. Durko, \& J. F. Petrick,. Journal of Travel Research, 1-15 (2015)

14. C. E. Ugouwanyi, Global Journal of Human-Social Science Research, 16(2). 31-45 (2016)

15. M. E. Clarkson, M. E. Academy of Management Review, 20(1), 92-117. (1995)

16. L. C. Hon, \& J. E. Grunig, Florida Institute of public relations. (1999)

17. S. C. Ting, Journal of Service Science and Management, 9(03), 276.(2016)

18. C. P. Lin, Y. H. Tsai, S. W. Joe, C. K. Chiu, Journal of business ethics, 105(1), 83-93. (2012)

19. S. M. Loureiro, I. M. D. Sardinha, L. Reijnders, Journal of Cleaner Production, 37, 172-178. (2012)

20. E. E. Izogo, Journal of Retailing and Consumer Services, 23, 107-117. (2015)

21. A. M. Durko, \& J. F. Petrick. Journal of Travel Research, 1-15 (2015)

22. L. Y. Do Thi Truc, Centria University of Applied Sciences, Kokkola; Thesis. (2016) 
23. A. Sharma, \& R. Kiran, African Journal of Basic \& Applied Sciences, 4(3), 95-105 (2012)

24. J. Bernard, Sociologia Ruralis, 55(2), 205-226. (2015)

25. A. S. Sengupta, M. S. Balaji, B. C. Krishnan, Journal of Business Research, 68(3), 665-674. ( 2015) 